\title{
Distribution of Starch Lysophosphatidylcholine in Pasting and Gelation of Wheat
}

\section{Starch Suspensions}

\author{
Masataka Ishinaga $^{1 *}$, Aiko Ueda ${ }^{2}$, Chie MatsunakA ${ }^{2}$ and Miho Tamura ${ }^{2}$ \\ ${ }^{1}$ Department of Health Sciences, Sanyo Women's College, 1-1, Sakata-Honmachi, Hatsukaichi, 738-8504, Japan \\ ${ }^{2}$ Department of Health Sciences, Prefectural University of Hiroshima, 1-1-71, Ujina-Higashi, Minami-ku. Hiroshima 734-8558, Japan
}

Received November 26, 2010; Accepted March 8, 2011

The amount and fatty acid composition of lysophosphatidylcholine (LPC) in the gelatinization, pasting and gelation of wheat starch were measured under a specific temperature program of a Rapid Visco Analyzer. The amount of LPC extracted from native starch in boiling water (HOT-LPC) with water-saturated $n$-butanol (WSB) was higher than that extracted at room temperature (RT-LPC). However, in the starch suspension at the beginning of gelatinization and in starch paste with increasing viscosity, the amounts of RT-LPC were higher than HOT-LPC. However, in starch paste with decreasing viscosity and starch gel, the amount of HOT-LPC was again higher than RT-LPC and similar to that of the native starch. The proportion of palmitic acid (PA) in HOT-LPC of starch paste with increasing viscosity was over $50 \%$. However, in HOT-LPC of native starch and starch gel, the proportion of PA was lower than that of linoleic acid. These results indicated that the distribution of starch LPC changed during gelatinization, pasting and gelation of wheat starch.

Keywords: wheat starch, amylose-lipid, lysophosphatidylcholine, fatty acid composition, pasting process

\section{Introduction}

The effects of amylose-lipid complexes on swelling, gelatinization, and retrogradation of starch have been studied using defatted starch (Eliasson and Krog, 1985; Eliasson and Wahgren, 2004; Gelders and Goesaert et al., 2006; Mira and Eliasson et al., 2005; Siswoyo and Morita, 2003; Takahashi and Seib, 1998; Tufvesson and Wahlgren et al., 2003). The effects of added emulsifiers are due to the formation of inclusion complexes between the amylose and emulsifiers. Although there have been many studies on the effects of amylose-lipid complexes on the rheological and thermal properties of starch, no study has examined starch phospholipids (PL) during gelatinization, pasting, and gelation of starch suspensions.

Over $90 \%$ of the internal starch lipids of wheat are lysophospholipid (LPL), of which lysophosphatidylcholine (LPC) accounts for $60-80 \%$ (Chung and Ohm, 2000; Morrison and Mann et al., 1975). It is well known that LPL forms inclusion complexes with amylose (Eliasson and Wahgren, 2004;

*To whom correspondence should be addressed.

E-mail: ishinaga@sanyo.ac.jp
Morrison, 1995; Tester and Morrison, 1990). The proportion of palmitic (PA) and linoleic (LA) acids in LPC is 35\% and $54 \%$, respectively (Chung and Ohm, 2000). However, studies on the addition of these lipids to defatted starch indicate that the stability of saturated fatty acid complexes is higher than that of unsaturated fatty acid complexes (Eliasson and Krog, 1985; Tufvesson and Wahlgren et al., 2003). Therefore, lipids composed of saturated fatty acids are used to form such complexes (Eliasson and Krog, 1985; Gelders and Goesaert et al., 2006; Siswoyo and Morita, 2003; Tufvesson and Wahlgren et al., 2003). These results do not reflect the fatty acid composition of the native complexes, and research into why there is such a discrepancy has not been undertaken.

On the other hand, lipids from amylose-lipid complexes of internal starch lipids can be extracted with hot aqueous alcohol (methanol, propanol, or $n$-butanol) in boiling water, but cannot be extracted at room temperature (Morrison and Mann et al., 1975; Morrison and Coventry, 1985). In a previously reported study, we showed that this does not apply to wheat flour paste (Ishinaga and Tuohuti et al., 2010). That is, in flour paste of increasing viscosity, the amount of LPC extracted at room temperature (RT-LPC) with water-saturated 
$n$-butanol (WSB) was greater than that of LPC thermally extracted in boiling water (HOT-LPC).

Furthermore, after the viscosity decreased, the amount of HOT-LPC was again greater than that of RT-LPC. The proportion of PA in HOT-LPC in the flour paste of increasing viscosity was $57 \%$, whereas that of HOT-LPC in flour was $43 \%$. Ours was the first demonstration of such a phenomenon.

The purpose of this study was to investigate whether the above-mentioned findings originate in the wheat protein or in the starch. That is, the distribution of LPL between RT- and HOT-lipid in gelatinization, pasting, and gelation of wheat starch was investigated.

\section{Materials and Methods}

Materials Wheat starch (moisture, 14\%) was kindly donated by the Association for Separation and Processing of Wheat Flour of Japan. The sample was divided (20 g each) into reagent bottles, and preserved at $5^{\circ} \mathrm{C}$. Authentic phosphatidylcholine (PC), phosphatidylserine, phosphatidylglycerol (PG), phosphatidylethanolamine (PE), phosphatidylinositol (PI) and their lysoforms were purchased from Sigma-Aldrich (St. Louis, MO, USA), Avanti Polar Lipid Inc. (Alabaster, AL, USA), Serdary Res. Lab. (Toronto, ON, Canada). TLC plates (Silica gel 60;1.05721.0009) were obtained from Merck (Darmstad, Germany). Standard fatty acid methyl esters (grain fatty acid methyl ester mix) and the methylation reagent $\left(\mathrm{BF}_{3} / \mathrm{CH}_{3} \mathrm{OH}, 14 \%\right.$ solution $)$ were obtained from Supelco Inc. (Bellefonte, PA, USA).

RVA Sampling for PL analysis at the beginning of gelatinization, pasting and gelation of the starch suspensions were carried out using a Rapid Visco Analyzer RVA 3D (RVA; Newport Scientific Pty. Ltd., NSW, Australia). The starchwater suspension contained $4 \mathrm{~g}$ of wheat starch in $26 \mathrm{~mL}$ of water. The starch suspension was stirred at $960 \mathrm{rpm}$ for $10 \mathrm{~s}$ and then maintained at $160 \mathrm{rpm}$ during the subsequent heating and cooling cycle. The starch suspension was stirred at $40^{\circ} \mathrm{C}$ for $5 \mathrm{~min}$, and subsequently heated to $95^{\circ} \mathrm{C}$ at a heating rate of $4^{\circ} \mathrm{C} / \mathrm{min}$, held at $95^{\circ} \mathrm{C}$ for $5 \mathrm{~min}$, cooled at a constant rate $\left(4^{\circ} \mathrm{C} / \mathrm{min}\right)$ to $50^{\circ} \mathrm{C}$, and held at $50^{\circ} \mathrm{C}$ for $5 \mathrm{~min}$. A starch pasting viscosity curve, corresponding to the extended temperature program, is shown in Figure 1. This profile was similar to the usual RVA profiles of wheat starch, though the program was different (Zeng and Morrison et al., 1997).

The starch suspension was freshly prepared prior to each use, and the RVA program was restarted. Sampling was performed at $40^{\circ} \mathrm{C}$ for $5 \mathrm{~min}$ (suspension), at $60^{\circ} \mathrm{C}$ (approximate beginning temperature of gelatinization), at $80^{\circ} \mathrm{C}$ and $90^{\circ} \mathrm{C}$ (early and late stages of increasing viscosity), while holding at $95^{\circ} \mathrm{C}$ for $5 \mathrm{~min}$ (decreasing viscosity), and at $50^{\circ} \mathrm{C}$ for 5 min (maximum viscosity during cooling). When the RVA completed at the programmed sampling times, $7.5 \mathrm{~g}$ (corresponding to $1 \mathrm{~g}$ native starch) of the suspension, paste, or gel was removed from the canister and placed in a roundbottomed tube.

\section{Lipid analysis}

(1) Lipid extraction Lipid extraction was basically carried out according to the method of Morrison and Mann et al. (1975). An 8-mL aliquot of WSB, containing $0.05 \mathrm{~mL}$ of $1 \%$ butylated hydroxytoluene, was added to a $50 \mathrm{~mL}$ roundbottom tube containing $7.5 \mathrm{~g}$ starch suspension, paste or gel, vigorously mixed for $30 \mathrm{~min}$ at RT (approx. $23^{\circ} \mathrm{C}$ ), and centrifuged for $20 \mathrm{~min}$ at $2500 \times \mathrm{g}$. After removal of the supernatant, the same volume of extraction solvent was again added to the residue, and the lipid (RT-lipid) was re-extracted in the same manner. The RT-lipid extraction was performed three times in total. After RT extraction three times, the same volume of extraction solvent was added to the residue, the lipids were extracted for $30 \mathrm{~min}$ in boiling water with occasional shaking (HOT-lipid), and following centrifugation the supernatant was withdrawn. An $8-\mathrm{mL}$ aliquot of extraction solvent was again added to the residue, and the lipid reextracted in boiling water. The extraction of the HOT-lipid was performed three times in total. The combined WSB fractions were dried by rotary vacuum evaporation and the extracted lipids were washed with $15 \mathrm{~mL}$ chloroform, $15 \mathrm{~mL}$ of methanol and $12 \mathrm{~mL}$ of $2 \% \mathrm{NaCl}$. The crude lipids were dissolved in $7 \mathrm{~mL}$ of chloroform, and stored at $-80^{\circ} \mathrm{C}$. In native starch samples, $1 \mathrm{~g}$ of starch was used for lipid extraction. The preparation of samples was performed in triplicate or quadruplicate.

(2) Determination of phospholipid phosphorus The content of phospholipid phosphorus (PL-Pi) in the crude lipid was determined using the method of Bartlett (1959).

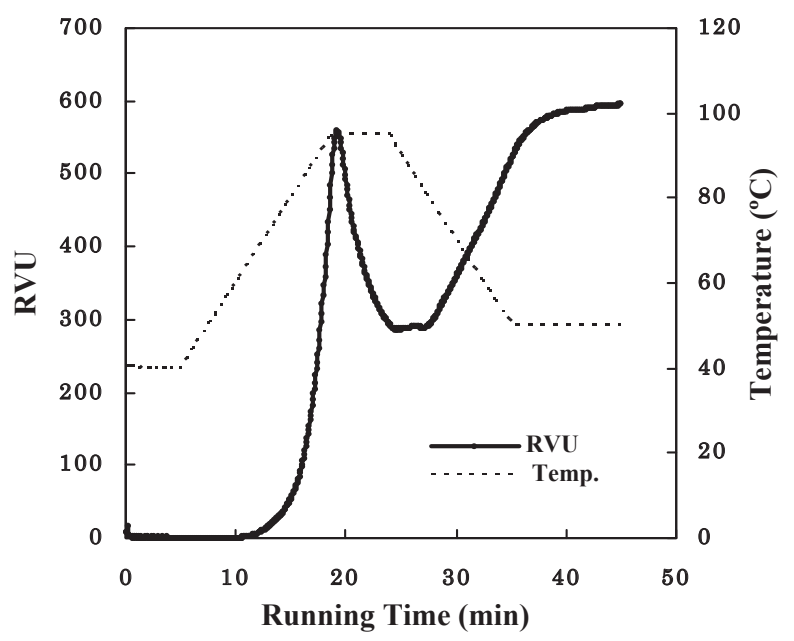

Fig. 1. Pasting profile of wheat starch water suspension $(0.154$ starch/water ratio) from a Rapid Visco Analyzer. 
Phospholipids were prepared from crude lipids separated by TLC with chloroform/methanol/acetic acid/water $(180: 150: 30: 10, \mathrm{v} / \mathrm{v})$ as the developing solvent (Ishinaga, and Sato et al., 1982; Ishinaga and Tuohuti et al., 2010). After developing with iodine vapor to visualize the spots, the spots were then carefully scraped from the plate with a razor blade. The PL-Pi content was determined using the method of Keenan and Schmidt et al. (1968).

Individual phospholipids were identified using Dittmer reagent and Ninhydrin spray, and by comparison with phospholipid standards as previously described (Ishinaga and Tuohuti et al., 2010). n-Acyl phosphatidylethanolamine (Acyl PE) and n-acyllysophosphatidylethanolamine (AcylLPE) were also identified as previously described (Ishinaga and Tuohuti et al., 2010).

(3) Analysis of fatty acid composition of LPC The crude lipid containing $0.2-0.3 \mathrm{mg}$ of PL-Pi was developed on TLC in parallel with phospholipid standards. When the total PL-Pi was $0.1 \mathrm{mg}$ or less, the crude lipid, which derived from $2-3 \mathrm{~g}$ of starch, was used. After evaporating the solvent from the plate in vacuo for $6 \mathrm{~h}$, the LPC standards were identified by exposing the plate to iodine vapor, and the sample spot corresponding to LPC was carefully scraped from the plate, placed in a screw-capped glass tube fitted with a Teflon cap, and $14 \% \mathrm{BF}_{3} /$ methanol was added for trans-methylation (Dougherty and Galli et al., 1987; Ishinaga and Tuohuti et al., 2010).

The fatty acid composition was analyzed by gas chromatography (GC14A; Shimadzu Corporation, Kyoto, Japan) with a DB-225 capillary column (length, $30 \mathrm{~m}$; i.d., 0.25 $\mathrm{mm}$; film, $0.25 \mu \mathrm{m}$; J\&M Scientific, Folsom, CA, USA). The column temperature was maintained at $180^{\circ} \mathrm{C}$ for the first min, then raised to $220^{\circ} \mathrm{C}$ at a rate of $3^{\circ} \mathrm{C} / \mathrm{min}$, and kept at this temperature for $25 \mathrm{~min}$. Identification of each fatty acid was done by comparison with standards (Ishinaga and Tuohuti et al., 2010). The system was controlled with the gas chromatography software CLASS-GC10 ver. 1.3 (Shimadzu Corporation, Kyoto, Japan).

Statistical analysis Measurements were performed in triplicate or quadruplicate and results expressed as mean \pm SD. Differences among sampling points were determined by one-way ANOVA $(\mathrm{P}<0.05)$. Individual differences between sampling points were determined using the Tukey-Kramer test. Differences of fatty acid composition in the sampling points between RT- and HOT-LPC were determined by Student's $t$ test $(\mathrm{P}<0.05)$. Statistical analyses were performed using Stat View 5.0 for Windows (SAS Institute).

\section{Results}

Pasting profile Figure 1 shows the pasting profile of the wheat starch-water suspension measured by a Rapid Visco Analyzer. Since the swelling of wheat starch granules begins at $45-50^{\circ} \mathrm{C}$ (Tester and Morrison, 1990) and at the same time amylose leaches from the granules (Eliasson and Wahgren, 2004; Morrison, 1995; Tester and Morrison, 1990), the starch suspension was held at $40^{\circ} \mathrm{C}$ for $5 \mathrm{~min}$. Though the temperature range at which the gelatinization occurs is generally $53-64^{\circ} \mathrm{C}$ (Cornell, 2004; Soulaka and Morrison, 1985 ) and pasting is defined as the phenomenon following gelatinization (Batey, 2007), it was estimated from the profile that the beginning temperature for gelatinization was approx. $60^{\circ} \mathrm{C}$ (Fig. 1). The starch paste showed peak viscosity when held at $95^{\circ} \mathrm{C}$ for $1 \mathrm{~min}$ and minimum viscosity at $25 \mathrm{~min}$ running time. Retrogradation began at approx. $4 \mathrm{~min}(27 \mathrm{~min}$ running time) after the starch paste began cooling from $95^{\circ} \mathrm{C}$ to $50^{\circ} \mathrm{C}$. The maximum viscosity was obtained at $40 \mathrm{~min}$ (holding for $5 \mathrm{~min}$ at $50^{\circ} \mathrm{C}$ ).

Phospholipid distribution in gelatinization, pasting and gelation of wheat starch-water suspension The amount of phospholipid extracted at RT (RT-PL) and the amount thermally extracted (HOT-PL) with WSB were measured during the beginning of gelatinization, pasting and gelation of wheat starch suspensions (Fig. 2).

The amounts of HOT-PL-Pi from native and starch sus-



Fig. 2. The distribution of PL extracted from wheat starch pastes during gelatinization, pasting, and gelation of wheat starch suspension ( $\mathrm{mg} / \mathrm{g}$ wheat starch).

Values are expressed as mean $\pm \mathrm{SD}(\mathrm{n}=3-4) \mathrm{of} \mathrm{mg} / \mathrm{g}$ wheat starch. Samples were extracted with WSB at room temperature $(\boldsymbol{\Delta}$; RT-PL), and in boiling water $(\bigcirc$; HOT-PL) from the residue. Letters indicate significant differences $(\mathrm{p}<0.05)$. Sampling was carried out at $5,10,15,17.5,23.8$, and 40 min running time, and the states of the starch suspensions correspond to: suspension $\left(40^{\circ} \mathrm{C}\right.$ for $\left.5 \mathrm{~min}\right)$, beginning of gelatinization $\left(60^{\circ} \mathrm{C}\right)$, early and late stages of increasing viscosity $\left(80^{\circ} \mathrm{C}\right.$ and $\left.90^{\circ} \mathrm{C}\right)$, decreasing viscosity (state holding at $95^{\circ} \mathrm{C}$ for $5 \mathrm{~min}$ ), and maximum viscosity during cooling (holding at $50^{\circ} \mathrm{C}$ for $5 \mathrm{~min}$ ), as described in the text. *NS: native starch. 
pension $(0.34 \mathrm{mg} / \mathrm{g}$ starch $)$ were over four times that of RTPL-Pi (0.06-0.08 mg/g starch). However, the amounts of RT-PL-Pi from the starch suspension at the beginning of gelatinization and during the starch paste with increasing viscosity were higher than those of HOT-PL-Pi. In the increased viscosity starch paste, RT-PL-Pi $(0.28-0.31 \mathrm{mg} / \mathrm{g}$ starch) increased to about double that of HOT-PL-Pi $(0.13-0.16 \mathrm{mg} / \mathrm{g}$ starch). When the viscosity of starch paste decreased (holding for $5 \mathrm{~min}$ at $95^{\circ} \mathrm{C}$ ), HOT-PL-Pi was again higher than RTPL-Pi. In the gel, RT- and HOT-PL-Pi were similar to that of native starch.

These results suggest that there were two forms of internal LPL in wheat starch granules.

Distribution of the phospholipid classes in gelatinization, pasting and gelation of wheat starch-water suspension Table 1 shows the phospholipid classes and amounts in RT- and HOT-PL. The major phospholipids were LPC and LPE, with LPC accounting for greater than $85 \%$ of the total phospholipid. LPC distribution is shown in Figure 3.

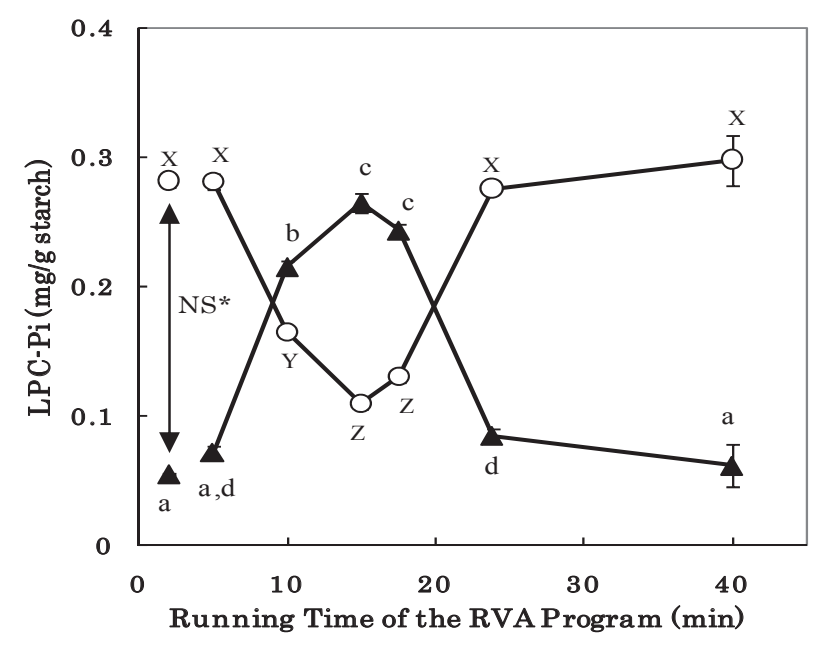

Fig. 3. The distribution of LPC extracted from wheat starch pastes during gelatinization, pasting, and gelation of wheat starch suspension ( $\mathrm{mg} / \mathrm{g}$ wheat starch).

Values are expressed as mean \pm SD $(n=3-4)$ of $\mathrm{mg} / \mathrm{g}$ wheat starch from the data in Table 1. See legend of Figure 2.

Table 1. Composition of phospholipid extracted from the starch paste during gelatinization, pasting, and gelation (PL-Pi $\mu \mathrm{g} / \mathrm{g}$ starch).

\begin{tabular}{|c|c|c|c|c|c|c|c|c|}
\hline \multirow[b]{3}{*}{ Phospholipid } & & & \multicolumn{6}{|c|}{ Running time of RVA programm } \\
\hline & \multicolumn{2}{|c|}{ Native Starch } & \multicolumn{2}{|c|}{$\begin{array}{c}5 \min \\
\left(40^{\circ} \mathrm{C}\right)\end{array}$} & \multicolumn{2}{|c|}{$\begin{array}{l}10 \mathrm{~min} \\
\left(60^{\circ} \mathrm{C}\right)\end{array}$} & \multicolumn{2}{|c|}{$\begin{array}{l}15 \mathrm{~min} \\
\left(80^{\circ} \mathrm{C}\right)\end{array}$} \\
\hline & $\mathrm{RT}^{*}$ & HOT & RT & HOT & RT & HOT & RT & HOT \\
\hline $\mathrm{LPC}^{* * *}$ & $54.8 \pm 0.4$ & $281.3 \pm 5.1$ & $71.4 \pm 4.7$ & $282.1 \pm 5.3$ & $215.0 \pm 4.3$ & $164.8 \pm 4.4$ & $264.6 \pm 7.1$ & $109.1 \pm 4.3$ \\
\hline $\mathrm{PC}+\mathrm{LPS}$ & $\mathrm{T}^{* *}$ & $\mathrm{~T}$ & $\mathrm{~T}$ & $\mathrm{~T}$ & $\mathrm{~T}$ & $\mathrm{~T}$ & $\mathrm{~T}$ & $\mathrm{~T}$ \\
\hline LPE & $4.4 \pm 0.7$ & $40.8 \pm 3.5$ & $6.2 \pm 0.9$ & $45.7 \pm 2.0$ & $20.9 \pm 1.9$ & $22.6 \pm 1.0$ & $34.8 \pm 3.7$ & $11.4 \pm 1.4$ \\
\hline $\mathrm{LPG}+\mathrm{PI}$ & $\mathrm{T}$ & $5.0 \pm 0.2$ & $\mathrm{~T}$ & $6.4 \pm 0.2$ & $4.7 \pm 0.2$ & $5.2 \pm 0.4$ & $4.3 \pm 0.2$ & $4.4 \pm 0.2$ \\
\hline $\mathrm{PE}+\mathrm{PG}$ & $\mathrm{T}$ & $\mathrm{T}$ & $\mathrm{T}$ & $\mathrm{T}$ & $\mathrm{T}$ & $\mathrm{T}$ & $\mathrm{T}$ & $\mathrm{T}$ \\
\hline Acytype PE & $\mathrm{T}$ & $\mathrm{T}$ & $\mathrm{T}$ & $\mathrm{T}$ & $\mathrm{T}$ & $\mathrm{T}$ & $\mathrm{T}$ & $\mathrm{T}$ \\
\hline
\end{tabular}

\begin{tabular}{|c|c|c|c|c|c|c|}
\hline \multirow[b]{3}{*}{ Phospholipid } & \multicolumn{6}{|c|}{ Running time of RVA programm } \\
\hline & \multicolumn{2}{|c|}{$\begin{array}{l}17.5 \mathrm{~min} \\
\left(90^{\circ} \mathrm{C}\right)\end{array}$} & \multicolumn{2}{|c|}{$\begin{array}{c}23.8 \mathrm{~min} \\
\text { (holding at } 95^{\circ} \mathrm{C} \text { for } 5 \mathrm{~min} \text { ) }\end{array}$} & \multicolumn{2}{|c|}{$\begin{array}{l}40 \mathrm{~min} \\
\text { (holding at } 50^{\circ} \mathrm{C} \text { for } 5 \mathrm{~min} \text { ) }\end{array}$} \\
\hline & $\mathrm{RT}$ & HOT & RT & HOT & RT & HOT \\
\hline $\mathrm{LPC}^{* * *}$ & $243.1 \pm 5.0$ & $130.0 \pm 3.8$ & $84.6 \pm 5.3$ & $275.3 \pm 8.2$ & $61.3 \pm 16.4$ & $297.8 \pm 19.3$ \\
\hline $\mathrm{PC}+\mathrm{LPS}$ & $\mathrm{T}$ & $\mathrm{T}$ & $\mathrm{T}$ & $\mathrm{T}$ & $\mathrm{T}$ & $\mathrm{T}$ \\
\hline LPE & $31.5 \pm 2.0$ & $18.1 \pm 1.3$ & $7.5 \pm 1.0$ & $37.5 \pm 4.4$ & $4.4 \pm 2.5$ & $43.5 \pm 4.7$ \\
\hline $\mathrm{LPG}+\mathrm{PI}$ & $4.9 \pm 0.0$ & $6.3 \pm 0.6$ & $\mathrm{~T}$ & $9.2 \pm 1.7$ & $\mathrm{~T}$ & $9.7 \pm 0.9$ \\
\hline $\mathrm{PE}+\mathrm{PG}$ & $\mathrm{T}$ & $\mathrm{T}$ & $\mathrm{T}$ & $\mathrm{T}$ & $\mathrm{T}$ & $\mathrm{T}$ \\
\hline Acytype PE & $\mathrm{T}$ & $\mathrm{T}$ & $\mathrm{T}$ & $\mathrm{T}$ & $\mathrm{T}$ & $\mathrm{T}$ \\
\hline
\end{tabular}

Values are expressed as means $\pm \mathrm{SD}(\mathrm{n}=3-4)$.

*: See legend of Figure 2.

**: T, less than $4 \mu \mathrm{g}$ (PL-Pi)/g starch. This value corresponds to approx. 1\% of the total amount of PL-Pi (about $400 \mu \mathrm{g} / \mathrm{g}$ starch).

***: PC, phosphatidylcholine; LPC, lysophosphatidylcholine; LPS, lysophosphatidylserine; PE, phosphatidylethanolamine; LPE, lysophosphatidylethanolamine; PG, phosphatidylglycerol; LPG, lysophosphatidylglycerol; PI, phosphatidylinositol; Acyltype PE, n-acylphosphatidylethanolamine and n-acyllysophosphatidylethanolamine. 
The amounts of RT- and HOT-LPC-Pi from native starch and starch suspension at $40^{\circ} \mathrm{C}$ were $55-71$ and $281-282$ $\mu \mathrm{g} / \mathrm{g}$ starch, respectively. When gelatinization of the starch suspension occurred at approx. $60^{\circ} \mathrm{C}$, the relative amount of RT- and HOT-LPC-Pi from the starch paste was reversed. RT-LPC-Pi increased to $215 \mu \mathrm{g} / \mathrm{g}$ starch, and HOT-LPC-Pi decreased to $165 \mu \mathrm{g} / \mathrm{g}$ starch. In the early and late stages of increasing viscosity, the RT-LPC-Pi of the paste increased to 265 and $243 \mu \mathrm{g} / \mathrm{g}$ starch, respectively. These values were twice those of HOT-LPC. Furthermore, when the viscosity of the starch paste decreased (holding for $5 \mathrm{~min}$ at $95^{\circ} \mathrm{C}$ ), the amount of HOT-LPC-Pi ( $275 \mu \mathrm{g} / \mathrm{g}$ starch) again increased to more than that of RT-LPC-Pi ( $85 \mu \mathrm{g} / \mathrm{g}$ starch). In the maximum viscosity starch gel, the amounts of RT- and HOTLPC-Pi were 61 and $298 \mu \mathrm{g} / \mathrm{g}$ starch, respectively, and these values were similar to those of the native starch. As shown in Figure 3, the changes in the amounts of RT-LPC and HOTLPC in paste were inversely proportional during the starch suspension pasting process.

The fluctuations in the amounts of LPE and LPG (starch LPL contains LysoPG rather than PI) were also almost the same as the LPC fluctuations (Table 1).

Fatty acid composition of LPC in gelatinization, pasting and gelation of wheat starch-water suspensions The fatty acid composition of RT-LPC and HOT-LPC during the pasting process of the starch suspension is shown in Table 2.

The LPC fatty acids consisted of PA, stearic, oleic, LA,

and linolenic acids. The proportions of PA and LA accounted for more than $80 \%$ of total fatty acid composition. In the gelatinization, pasting, and gelation stages, the proportions of PA and LA in RT-LPC from starch paste were 32 $35 \%$ and $52-57 \%$, respectively. These values were almost the same as those in native starch. However, the proportions of PA in HOT-LPC in the starch suspension at the beginning of the gelatinization, and in the starch paste of increasing viscosity, increased to $47-53 \%$, whereas the proportions of LA

Table 2. Composition of phospholipid extracted from the starch paste during gelatinization, pasting, and gelation (PL-Pi $\mu \mathrm{g} / \mathrm{g}$ starch).

\begin{tabular}{|c|c|c|c|c|c|c|c|c|}
\hline \multirow[b]{3}{*}{ Fatty acid } & & & \multicolumn{6}{|c|}{ Running time of RVA programm } \\
\hline & \multicolumn{2}{|c|}{ Native Starch } & \multicolumn{2}{|c|}{$\begin{array}{c}5 \min \\
\left(40^{\circ} \mathrm{C}\right)\end{array}$} & \multicolumn{2}{|c|}{$\begin{array}{l}10 \mathrm{~min} \\
\left(60^{\circ} \mathrm{C}\right)\end{array}$} & \multicolumn{2}{|c|}{$\begin{array}{l}15 \mathrm{~min} \\
\left(80^{\circ} \mathrm{C}\right)\end{array}$} \\
\hline & RT & HOT & RT & HOT & $\mathrm{RT}$ & HOT & RT & HOT \\
\hline $16: 0$ & $37.0 \pm 1.0$ & $37.7 \pm 1.0$ & $36.9 \pm 0.6$ & $38.7 \pm 0.3$ & $32.1 \pm 0.6$ & $47.2 \pm 0.4^{*}$ & $32.9 \pm 0.6$ & $52.7 \pm 1.2 *$ \\
\hline 18:0 & $0.8 \pm 0.2$ & $1.0 \pm 0.1$ & $0.8 \pm 0.0$ & $1.4 \pm 0.4^{*}$ & $0.6 \pm 0.0$ & $1.9 \pm 0.0^{*}$ & $0.5 \pm 0.0$ & $2.5 \pm 0.1 *$ \\
\hline $18: 1$ & $7.0 \pm 2.6$ & $8.2 \pm 1.3$ & $5.8 \pm 0.0$ & $9.0 \pm 0.1^{*}$ & $5.8 \pm 0.3$ & $12.3 \pm 0.1^{*}$ & $7.2 \pm 0.1$ & $11.5 \pm 0.4^{*}$ \\
\hline $18: 2$ & $51.4 \pm 3.0$ & $49.1 \pm 1.9$ & $52.4 \pm 0.3$ & $46.9 \pm 0.3^{*}$ & $57.4 \pm 0.4$ & $35.3 \pm 0.3^{*}$ & $55.3 \pm 0.6$ & $30.0 \pm 0.8^{*}$ \\
\hline $18: 3(\mathrm{n} 3)$ & $2.5 \pm 0.3$ & $2.3 \pm 0.2$ & $2.6 \pm 0.1$ & $2.1 \pm 0.0$ & $2.9 \pm 0.1$ & $1.1 \pm 0.0^{*}$ & $2.7 \pm 0.0$ & $1.0 \pm 0.0^{*}$ \\
\hline Unkown & $0.4 \pm 0.0$ & $0.9 \pm 0.3$ & $0.7 \pm 0.0$ & $0.9 \pm 0.0$ & $0.7 \pm 0.1$ & $1.2 \pm 0.0$ & $0.7 \pm 0.1$ & $1.2 \pm 0.0$ \\
\hline Other** & 0.9 & 0.9 & 1 & 0.8 & 0.5 & 1 & 0.7 & 1.2 \\
\hline
\end{tabular}

\begin{tabular}{|c|c|c|c|c|c|c|}
\hline \multirow[b]{3}{*}{ Fatty acid } & \multicolumn{6}{|c|}{ Running time of RVA programm } \\
\hline & \multicolumn{2}{|c|}{$\begin{array}{l}17.5 \mathrm{~min} \\
\left(90^{\circ} \mathrm{C}\right)\end{array}$} & \multicolumn{2}{|c|}{$\begin{array}{l}23.8 \mathrm{~min} \\
\text { (holding at } 95^{\circ} \mathrm{C} \text { for } 5 \mathrm{~min} \text { ) }\end{array}$} & \multicolumn{2}{|c|}{$\begin{array}{l}40 \mathrm{~min} \\
\text { (holding at } 50{ }^{\circ} \mathrm{C} \text { for } 5 \mathrm{~min} \text { ) }\end{array}$} \\
\hline & RT & HOT & RT & HOT & RT & HOT \\
\hline $16: 0$ & $31.8 \pm 0.6$ & $52.1 \pm 0.5^{*}$ & $34.6 \pm 3.1$ & $41.5 \pm 1.5^{*}$ & $32.7 \pm 0.3$ & $42.9 \pm 1.2 *$ \\
\hline 18:0 & $0.5 \pm 0.0$ & $2.4 \pm 0.0^{*}$ & $0.5 \pm 0.0$ & $1.3 \pm 0.1 *$ & $0.5 \pm 0.0$ & $1.5 \pm 0.1 *$ \\
\hline $18: 1$ & $7.3 \pm 0.5$ & $11.7 \pm 0.1^{*}$ & $6.7 \pm 0.2$ & $9.3 \pm 0.7^{*}$ & $6.9 \pm 0.1$ & $10.3 \pm 0.5^{*}$ \\
\hline $18: 2$ & $56.4 \pm 0.6$ & $30.5 \pm 0.5^{*}$ & $53.6 \pm 2.4$ & $44.6 \pm 1.2 *$ & $55.5 \pm 0.3$ & $42.1 \pm 1.3^{*}$ \\
\hline $18: 3(\mathrm{n} 3)$ & $2.8 \pm 0.0$ & $1.0 \pm 0.0^{*}$ & $3.1 \pm 0.6$ & $1.9 \pm 0.1^{*}$ & $2.9 \pm 0.0$ & $1.7 \pm 0.1 *$ \\
\hline Unkown & $0.7 \pm 0.0$ & $1.2 \pm 0.0$ & $0.7 \pm 0.0$ & $0.9 \pm 0.0$ & $0.7 \pm 0.0$ & $1.0 \pm 0.0$ \\
\hline Other** & 0.7 & 1.2 & 0.8 & 0.8 & 0.7 & 0.9 \\
\hline
\end{tabular}

Values are expressed as means $\pm \mathrm{SD}(\mathrm{n}=3-4)$.

*: Significant different between RT and HOT $(\mathrm{p}<0.05)$.

$* *$ : Fatty acids present at levels of $<1 \%$ in both RT and HOT were 14:0, 15:0, 17:0 and 20:1.

See legends of Figure 2 and Table 1. 
in HOT-LPC decreased to $30-35 \%$. In the starch paste of decreasing viscosity through to the peak viscosity and in the starch gel, the proportions of PA and LA in HOT-LPC were $42-43 \%$ and $42-45 \%$, respectively, and these values were similar to those in native starch.

\section{Discussion}

In a previous study, we were the first to report that during the pasting process of a wheat flour-water suspension, changes in the amounts of RT- and HOT-LPC were inversely proportional and their fatty acid composition, especially the proportions of PA and LA, also changed (Ishinaga and Tuohuti et al., 2010). Furthermore, we demonstrate in this paper that this phenomenon originates not in the wheat protein but in the starch.

The distribution between RT- and HOT-lipid, of PL and LPL in starch paste during the pasting process, is shown in Figure 2 and Table 1. More than 95\% of the amount of PL in starch was comprised of LPL. More than $85 \%$ of LPL was comprised of LPC, with approx. 10\% being LPE. These results are in accordance with other reports (Chung and Ohm, 2000).

It is well known that the amount of HOT-PL extracted with hot WSB from native starch is markedly higher than that of RT-PL extracted with WSB at RT (Fig. 2 and Table 1) (Chung and Ohm, 2000; Morrison and Mann et al., 1975). The HOT-PL is an internal starch lipid and is generally thought to exist as an amylose-LPL complex (Morrison, 1995). However, as shown in Figures 2 and 3, in the starch suspension at the beginning of gelatinization and in the starch paste with increasing viscosity, the amounts of RT-PL and -LPC significantly exceeded those of HOT-PL and -LPC. This phenomenon is contrary to current thinking, since the internal starch lipid amylose-LPL complexes are thought to be extractable only with hot alcohol (Morrison and Coventry, 1985). On the other hand, when the starch-water suspension was held at $40^{\circ} \mathrm{C}$ for $5 \mathrm{~min}$, the amounts of RT- and HOT$\mathrm{PL}$ in the suspension were similar to those in native starch. Therefore, it is necessary for the starch to be gelatinized for the LPC of the HOT-PL to be recovered as RT-PL. We draw the following inferences from this phenomenon.

Continuous heating of native starch granules above a certain temperature in excessive water results in its gradual swelling and the leaching of amylose (Morrison, 1995; Morrison and Tester et al., 1993). At that time, the rigid and organized structure of the native starch granules (Gallant and Bouchet et al., 1997; Pérez and Bertoft, 2010) will change into a loose structure, and the LPC that is enclosed in the rigid structure may become easily accessible and thus can easily be extracted at RT. LPC enclosed in the rigid structure, not the inclusion complexes with LPC and amylose, may not be detectable in crystallographic patterns with X-ray diffraction. Although Morrison and Tester et al. (1993) showed that the internal starch lipids of barley are fully formed complexes with amylose, this has not been demonstrated in wheat starch.

Another possibility was discussed as follows. Elliason (1980) demonstrated that when the water content of the wheat starch increases from $35 \%$ to $80 \%$, endothermic transition temperatures of amylose-lipid complexes decreased from $106^{\circ} \mathrm{C}$ to $70^{\circ} \mathrm{C}$ and from $140^{\circ} \mathrm{C}$ to $100^{\circ} \mathrm{C}$, respectively. These temperatures probably originate in the structure of type 1 and type 2 of the complexes, respectively (Eliasson and Krog, 1985; Eliasson, 1994; Biliarderis, 1992). Since the type 1 structure is an amorphous state, when wheat starch was gelatinized in excessive water (over $85 \%$ in our case), interactions between amylose and LPL in the complex will be weakened. As the result, LPL of amylose-LPL complexes of the type 1 form could be extracted with WSB at RT.

On the other hand, several studies have demonstrated the existence of complexes of the outer branches of amylopectin and polar lipids (Eliasson, 1994; Eliasson and Wahgren, 2004; Villwock and Eliasson et al., 1999). These amylopectin-lipid complexes will not behave in a manner similar to that of the amylose-lipid complexes (Eliasson and Wahgren, 2004). Although a relationship seems to exist between amylopectin and increasing LPC in the RT-PL, further data is required to clarify this matter.

The proportions of PA (38\%) and LA (49\%) in native starch (Table 2) were in accordance with previously reported values (Chung and Ohm, 2000). However, as shown in Table 2, the fatty acid proportions of HOT-LPC from the starch suspension at the beginning of gelatinization and from starch paste of increasing viscosity were significantly different from the values of native starch and starch suspensions $\left(40^{\circ} \mathrm{C}\right.$ for $\left.5 \mathrm{~min}\right)$. The proportion of PA increased from $38 \%$ to $47-53 \%$, and, conversely, LA decreased from $49 \%$ to $30-35 \%$. In these cases, the HOT-LPC (derived from the HOT-PL fraction) was recovered in the RT-PL fraction and was approx. three times that of RT-LPC derived from native starch. However, the fatty acid composition of RT-LPC from these starch pastes was similar to that of native starch. These results indicated that LPC with the same fatty acid composition as that from native starch transitioned from HOT-LPC to RT-LPC. On the other hand, the proportion of PA in HOTLPC from starch paste with increasing viscosity was greater than that of RT-LPC, and the proportion of LA was lower. Therefore, HOT-LPC from starch paste during increasing viscosity forms stable amylose-lipid complexes because it mainly consists of saturated fatty acids (Eliasson and Krog, 
1985; Tufvesson and Wahlgren et al., 2003).

These results suggest that there are two forms of LPL in the internal lipid of starch granules. One is the stable LPL formed in polysaccharide-lipid complexes with the LPC containing saturated fatty acid. The other is the free or unstably bound LPL form that changes into a state that is easily extracted at RT from the starch suspension at the beginning of gelatinization and from the starch paste of increasing viscosity, in which LPC contains unsaturated fatty acid.

When the starch paste decreased in viscosity (holding at $95^{\circ} \mathrm{C}$ for $5 \mathrm{~min}$ ) and gelled (holding at $50^{\circ} \mathrm{C}$ for $5 \mathrm{~min}$ ), the amounts of PL and LPC from the starch paste and gel, and the fatty acid composition of the LPC, were similar to those of native starch (Figs. 2 and 3). This result suggested that the starch paste with decreasing viscosity might have gelled during the experimental procedure. The temperature of the sample decreases rapidly from $95^{\circ} \mathrm{C}$ to near RT, because a few minutes are required from the stop of the RVA program to the WSB addition. As a result, it is highly possible that the starch paste with decreasing viscosity, where high levels of amylose exist, has resulted in retrogradation. During holding at $95^{\circ} \mathrm{C}$ for $5 \mathrm{~min}$, amylose-LPL complexes might again be reassociated between dispersed LPL and amylose (Singh and Singh et al., 2008), or free LPL in the starch paste might be incorporated in polysaccharide aggregates or/and ghost granules during retrogradation. In the case of wheat flour, lipids other than LPL, such as AcylPE and AcylLPE, should also be incorporated in the aggregates (Ishinaga and Tuohuti et al., 2010).

On the other hand, the amounts of RT-PL and -LPC from starch paste with decreasing viscosity and gel (maximum viscosity) did not decrease more than those of native starch (Figs. 2 and 3). This suggests that the RT-LPC from native starch, which is a starch surface lipid, binds to components, likely to be proteins, on the starch surface. This is supported by Wilde and Clark et al. (1993), who reported that puroindoline is associated with LPC molecules in vitro.

The observed re-distribution of LPC content between RT- and HOT-PL and the changes in fatty acid composition of LPC during gelatinization, pasting, and gelation of starch suspensions will help clarify the relationship between polysaccharide and LPL in the pasting process of wheat starch.

Acknowledgements This work was supported by KIEIKAI Research Foundation. We also would like to thank Prof. M. Kugimiya (Kurashiki Sakuyo University) for helpful comments.

\section{References}

Bartlett, G.R. (1959). Phosphorus assay in column chromatography. J. Biol. Chem., 34, 466-468.
Batey, I.L. (2007). Interpretation of RVA curves. In "The RVA Handbook" ed. by Graham, B.C. and Andrew, S.R. AACC International Press, MN, pp. 19-30.

Biliarderis, C.G. (1992). Structure and phase transitions of starch in food system. Food Technol., 46, 98-109.

Chung, O.K. and Ohm, J.B. (2000). Cereal lipids. In "Handbook of Cereal Science and Technology, 2nd ed." ed. by K. Kulp and J.G. Pont. Marcel Dekker, Inc., NY, pp. 417-477.

Cornell, H. (2004). The functionality of wheat. In "Starch in Food: Structure, Function and Applications" ed. by A.C. Eliasson. CRC Press, NY, pp. 211-240.

Dougherty, R.M., Galli, C., Ferro-Luzzi, A. and Iacono, J.M. (1987). Lipid and phospholipid fatty acid composition of plasma, red blood cells, and platelets and how they are affected by dietary lipids: a study of normal subjects from Italy, Finland, and the USA. Am. J. Clin. Nutr., 45, 443-455.

Eliasson, A.C. (1980). Effect of water content on the gelatinization of wheat starch. Starch, 32, 270-272.

Eliasson, A.C. (1994). Interactions between starch and lipids studied by DSC. Thermochimica Acta, 246, 343-356.

Eliasson, A.C. and Krog, N. (1985). Physical properties of amylosemonoglyceride complexes. J. Cereal Sci., 3, 239-248.

Eliasson, A.C. and Wahgren, M. (2004). Starch-lipid interactions and their relevance in food products. In "Starch in Food: Structure, Function and Applications" ed. by A.C. Eliasson. CRC Press, NY, pp. 441-460.

Gallant, D.J., Bouchet, B. and Baldwin, P.M. (1997). Microscopy of starch: evidence of a new level of granule organization. Carbohydrate polymers, 32, 177-191.

Gelders, G.G., Goesaert, H. and Decour, J.A. (2006). Amylose-lipid complexes as controlled lipid release agents during starch gelatinization and pasting. J. Agric. Food Chem., 54, 1493-1499.

Ishinaga, M., Sato, J., Kitagawa, Y., Sugimoto, E. and Kito, M. (1982). Perturbation of phospholipid metabolism by erucic acid in male Sprague-Dawley rat heart. J. Biochem., 92, 253-263.

Ishinaga, M., Tuohuti,R., Ueda, A., Ohama, M., Matsuda, Y. and Sugiyama, S. (2010). Distribution of phospholipid during gelatinization process of wheat flour suspension. Nippon Shokuhin Kagaku Kogaku Kaishi, 57, 288-295 (in Japanese).

Keenan, R.W., Schmidt, G. and Tanaka, T. (1968). Quantitative determination of phosphatidal lethanolamine and other phosphatides in various tissues of the rat. Anal. Biochem., 23, 555-566.

Mira, I., Eliasson, A.C. and Persson, K. (2005). Effect of surfactant structure on the pasting properties of wheat flour and starch suspensions. Cereal Chem., 82, 44-52.

Morrison, W.R. (1995). Starch lipids and how they related to starch granule structure and functionality. Cereal Foods World, 40, 437446.

Morrison, W.R. and Coventry, A.M. (1985). Extraction of lipids from cereal starches with hot aqueous alcohols. Starch, 37, 83- 
87.

Morrison, W.R., Mann, D.L., Soon, W. and Coventy, A.M. (1975). Selective extraction and quantitative analysis of non-starch and starch lipids from wheat flour. J. Sci. Food Agric., 26, 507-521.

Morrison, W.R., Tester, R.F., Snape, C.E., Law, R. and Gidley, M.J. (1993). Swelling and gelatinization of cereal starches. IV. Some effects of lipid-complexed amylose and free amylose in waxy and normal barley starches. Cereal Chem., 70, 385-391.

Pérez, S. and Bertoft, E. (2010). The molecular structures of starch components and their contribution to the architecture of starch granules: A comprehensive review. Starch, 62, 389-420.

Singh, S., Singh, G., Singh, P. and Singh, N. (2008). Effect of water stress at different stages of grain development on the characteristics of starch and protein of different wheat varieties. Food Chem., 108, 130-139.

Siswoyo, T.A. and Morita, N. (2003). Thermal properties of partially hydrolyzed starch- glycerophosphatidylcholine complexes with various acyl chains. J. Agric. Food Chem., 51, 3162-3167.

Soulaka, A.B. and Morrison, E.R. (1985). The amylose and lipid contents, dimensions, and gelatinisation characteristics of some wheat starches and their A- and B-granule fractions. J. Sci. Food
Agric., 36, 709-718.

Takahashi, S. and Seib, P.A. (1988). Paste and gel properties of prime corn and wheat starches with and without native lipids. $\mathrm{Ce}$ real Chem., 65, 474-483.

Tester, R.F. and Morrison, W.R. (1990). Swelling and gelatinization of cereal starches. I. Effects of amylopectin, amylose, and lipids. Cereal Chem., 67, 551-557.

Tufvesson, F., Wahlgren, M. and Eliasson, A.C. (2003). Formation of amylose-lipid complexes and effects of temperature treatment. Part 2. Fatty acids. Starch, 55, 138-149.

Villwock, V.K., Eliasson, A.C., Silverio, J. and BeMiller, J.N. (1999). Starch-lipid interactions in common, waxy, ae du, and ae su2 maize starches examined by differential scanning calorimetry. Cereal Chem., 76, 292-298

Wilde, P.J., Clark, D.C. and Marion, D. (1993). Influence of competitive adsorption of a lysopalmitoylphosphatidylcholine on the functional properties of puroindoline, a lipid-binding protein isolated from wheat flour. J. Agric. Food Chem., 41, 1570-1576.

Zeng, M., Morris, C.F., Batey, I.L. and Wrigley, C.W. (1997). Sources of variation for starch gelatinization, pasting, and gelation properties in wheat. Cereal Chem., 74, 63-71. 